\title{
Women in UK cardiology: report of a Working Group of the British Cardiac Society
}

\author{
A D Timmis, C Baker, S Banerjee, A L Calver, A Dornhorst, K M English, J Flint, M E Speechly-Dick, \\ D Turner
}

Heart 2005;91:283-289. doi: 10.1136/hrt.2004.047340

\begin{abstract}
A. INTRODUCTION
The first woman to appear on the British medical register was Elizabeth Blackwell in 1859, who had qualified earlier in New York. Later Elizabeth Garrett, disbarred like all women in the UK from attending medical school, passed examinations for the licentiate of the Society of Apothecaries and was admitted to the register in 1865. The call-up of doctors during the first world war allowed more women to enter the profession and by the mid 1940s they constituted $20 \%$ of all doctors. Thereafter there was little change for 30 years, when numbers of women entering UK medical schools started to increase to the point that they came to outnumber men during the 1990s. Despite this, women remain underrepresented in many hospital specialties, particularly cardiology, where they constitute only $16.8 \%$ of trainees and $7.4 \%$ of consultants. The failure of cardiology to attract such a large proportion of the talent pool prompted the British Cardiac Society to establish this working group, whose remit has been to identify the scale of the problem and the reasons for it to develop strategies for improving recruitment and retention of female cardiologists.
\end{abstract}

\section{B. WOMEN IN CARDIOLOGY - ANALYSIS OF THE FACTS \\ 1. Application and admission to medical school}

Although the total number of applications to medical school has not changed substantially in recent years, the proportion of female applicants has increased from $50.5 \%$ in 1996 to $58.8 \%$ in 2002 (table 1). ${ }^{1}$ Not only did more women than men apply for medical school in 2002 but proportionately more women were successful $(60.4 \% v 55.3 \%)$ and there may now be positive selection bias in favour of women at the point of application. Thus, women applying to UK medical schools in 1996-7 were 1.57 times more likely to be offered a place than similarly qualified men. ${ }^{2}$

Data on dropouts from UK medical schools are scant, a study from Leeds suggesting rates of 14\% between 1983 and 1992, with slightly more men than women leaving. ${ }^{3}$ Among British medical graduates, however, the situation may be different. A British Medical Association longitudinal study of 545 doctors who had qualified in 1995 reported that women accounted for six of seven doctors who had left medicine permanently and for all of the 12 respondents who cited childcare as the reason for temporarily leaving the workforce. ${ }^{4}$

\section{Career aspirations of UK medical graduates}

A 1993 postal survey of the career preferences of UK graduates had responses from 2621 (71.7\%), of whom $21.5 \%$ were targeting careers in specialist hospital medicine. ${ }^{5}$ Cardiology was the most popular specialty choice and was the ambition of $10.3 \%$ of those targeting hospital medicine. Though cardiology was more popular with men, women represented $27.5 \%$ of those favouring cardiology compared with only $5.2 \% 10$ years earlier. This apparent increase in the popularity of cardiology among women must in part reflect the overall increase in female graduates during that period and accords with data from 2002 when women represented $10.0 \%$ of consultant cardiologists aged $<45$ but only $5.2 \%$ of consultant cardiologists aged $>45 .^{6}$

\section{Career choice in the UK: analysis of specialist registrars}

Deanery data for England and Wales in 2003 show that, of 358 cardiology specialist registrars (SpRs) with a national training number, only 60 (16.8\%) were women, a substantial shortfall on the career aspirations of preregistration house officers reported by Lambert et al, where $27.5 \%$ of those favouring cardiology were women. ${ }^{5}$

The London Deanery data in table 2 show that only $29 \%$ of all applications for SpR training posts from July 2001 to March 2003 were from women. However, the quality of applications from women appears to have been superior to those from men, since women accounted for $37 \%$ and $42 \%$ of candidates interviewed and appointed, respectively. This contrasts with the data for cardiology SpR training posts, where women accounted for only $9 \%$ and $8 \%$ of candidates interviewed and appointed, respectively. No flexible cardiology training appointments were made to the London Deanery from July 2001 to March 2003.

\section{Flexible training}

Flexible training is intended for those SpRs for whom full time work would not be practicable, usually for domestic or health reasons. Although flexible training is not restricted to women with children, they are the largest group and nationally constitute $>95 \%$ of all flexible trainees (UK Deaneries database 2002). However, access to flexible training is a problem and, since the new pay deal (1 December 2000), trusts have been unwilling to support it. Thus, flexible trainees working $<40$ hours a week are now paid in band F, but by doing out of hours work are paid more, often earning as much as their full time colleagues, while working fewer hours.

Differences in funding systems between deaneries have introduced significant geographical variation in flexible training opportunities, and at present there are insufficient places to meet demand. In 2002 the Department of Health identified an additional $£ 7$ million to enable deaneries to make a greater contribution to flexible training salaries from August 2002, and a further $£ 7$ million will be available in 2003-4. No further deanery money has been identified beyond this date and, without continuing ring fenced funding, the existing allocation will not be sufficient to support all flexible posts on a supernumerary basis. Some help will be provided by the new Flexible Careers Scheme set up as part of the Improving Working Lives Initiative. ${ }^{7}$ It will fund trainees for up to 19 hours a week for a maximum of 
Table 1 Acceptance of applicants to medical schools in the UK, 1996 and 2002

\begin{tabular}{|c|c|c|c|c|c|}
\hline \multirow[b]{2}{*}{ Year } & \multicolumn{2}{|c|}{ Applicants } & \multicolumn{3}{|c|}{ Acceptances } \\
\hline & Number & $\begin{array}{l}\text { Proportion of } \\
\text { all applicants }\end{array}$ & Number & $\begin{array}{l}\text { Proportion of } \\
\text { all acceptances }\end{array}$ & $\begin{array}{l}\text { Proportion of } \\
\text { applications by } \\
\text { gender }\end{array}$ \\
\hline \multicolumn{6}{|l|}{1996} \\
\hline All & 12025 & $100 \%$ & 4894 & $100 \%$ & $40.7 \%$ \\
\hline Men & 5950 & $49.5 \%$ & 2230 & $45.6 \%$ & $37.5 \%$ \\
\hline Women & 6075 & $50.5 \%$ & 2664 & $54.4 \%$ & $43.9 \%$ \\
\hline \multicolumn{6}{|l|}{2002} \\
\hline All & 11935 & $100 \%$ & 6959 & $100 \%$ & $58.3 \%$ \\
\hline Men & 4921 & $41.2 \%$ & 2723 & $39.1 \%$ & $55.3 \%$ \\
\hline Women & 7014 & $58.8 \%$ & 4236 & $60.9 \%$ & $60.4 \%$ \\
\hline
\end{tabular}

two years, which will be helpful but not sufficient to meet the funding requirements of all those wishing to train flexibly.

Flexible training is used widely in certain specialties such as anaesthetics, psychiatry, and paediatrics, each of which had > 130 trainees in this category entered on the UK Deaneries database in 2002. In cardiology, however, there were only six SpRs entered on the same database as flexible trainees. Career implications of flexible training are unclear.

\section{Career progression: consultants}

In 1987 a report of the proportions of women in hospital careers in England and Wales concluded, "The record suggests that being female is a handicap to achieving consultant status, particularly in the popular specialities". ${ }^{\prime}$ More recent studies of specialist career progression in the UK, ${ }^{9}$ however, suggest there is no "glass ceiling" and that the paucity of women consultants overall reflects historical trends in the numbers of women entering medical school. The evidence does not always support this view and in some specialities such as surgery there is a discrepancy between expressed career preferences and the numbers of female SpRs, suggesting that women have been deterred from continuing with a career in surgery. The same is true of women in cardiology, where career aspirations of preregistration house officers fall short of the numbers entering specialist training programmes and achieving consultant status. In the British Medical Association's study of 545 doctors who had qualified in $1995,{ }^{4}$ the most common reason given for changing career preference was "hours of work and working conditions" ( $8 \%$ of respondents). Thus, although the gap between the cardiological aspirations of female graduates and the numbers actually entering the specialty may reflect

Table 2 Specialist registrar applications and appointments (London Deanery July 2001 to March 2003)

\begin{tabular}{ccc}
\hline & \multicolumn{2}{l}{ Specialty } \\
\cline { 2 - 3 } & All & $\begin{array}{l}\text { Cardiology } \\
\text { (6 committees) }\end{array}$ \\
\hline $\begin{array}{c}\text { Applicants } \\
\text { Men } \\
\text { Women }\end{array}$ & $3701(71 \%)$ & $185(91 \%)$ \\
Shortlisted & $1560(29 \%)$ & $18(9 \%)$ \\
Men & $1464(63 \%)$ & $60(90 \%)$ \\
Women & $866(37 \%)$ & $7(10 \%)$ \\
Interviewed & $1335(63 \%)$ & $58(89 \%)$ \\
Men & $791(37 \%)$ & $7(11 \%)$ \\
Women & $709(58 \%)$ & $35(92 \%)$ \\
Appointed & $523(42 \%)$ & $3(8 \%)$ \\
Men & & \\
Women & & \\
\hline
\end{tabular}

multiple factors (see below), it is clear that a virtual ceiling composed of long, family unfriendly hours can be as hard to penetrate as one made of glass.

Royal College of Physicians census data for the workforce in medical specialties (England, Wales, and Ireland) from 1993 to 2002 show a progressive increase in the total consultant numbers from 3854 to $6711 .{ }^{6}$ Although women constitute the minority group, proportions have increased from $11.5 \%$ to $20.4 \%$ during the same period; in the age group $<45$ women constituted $27.3 \%$ of the 2002 consultant workforce. The census also shows an increasing number of consultant cardiologists, total numbers increasing from 381 in 1993 to 665 in 2002. However, women were significantly underrepresented (fig 1), constituting only $5.0 \%$ of the cardiology consultant workforce in 1992 and rising to $7.5 \%$ in 2002; in the age group $<45$ women constituted $10.0 \%$ of consultant cardiologists in 2002.

Data on part time working are now becoming available. The 2002 Royal College census shows that, of $9.2 \%$ of consultant physicians working part time, $46.6 \%$ were women. In that year, 38 of $451(8.4 \%)$ consultant cardiologists for whom data are available worked part time, of whom four (10.5\%) were women (table 3 ). These data provide no insight into reasons for working part time, but possibilities include private practice, domestic arrangements, and ill health. The census for 2003 will clarify this important point. Also unknown are the career implications of working part time.

\section{Cardiological politics}

Even allowing for the under representation of women in the specialty, their involvement in cardiological politics has been very low. During the past decade, no woman held office for

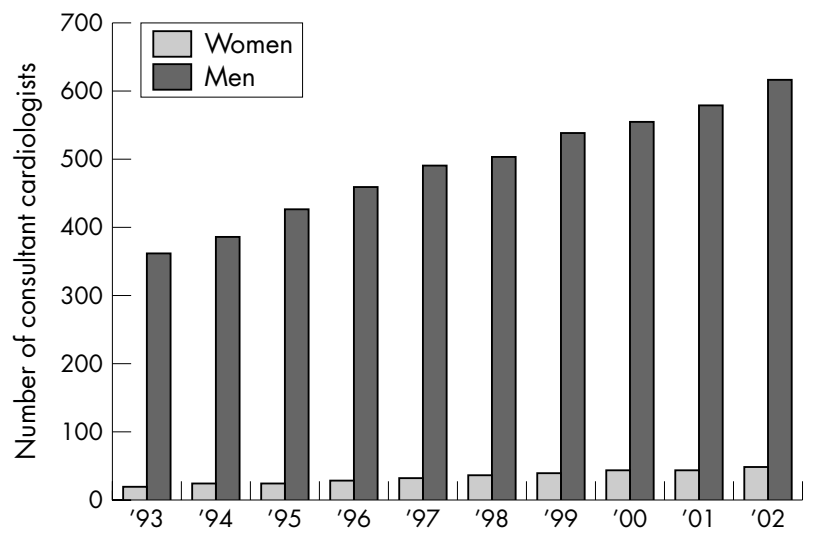

Figure 1 Consultant cardiologists by gender in England, Wales, and Northern Ireland, 1993-2002. Source: Royal College of Physicians Consultant Census. ${ }^{\circ}$ 
Table 3 Breakdown of number of cardiologists working full time, part time, and maximum part time

\begin{tabular}{lrcc}
\hline & Men & Women & Total \\
\hline Part time & 34 & 4 & 38 \\
Maximum part time & 168 & 8 & 176 \\
Full time & 214 & 23 & 237 \\
No answer & 266 & 20 & 286 \\
Total & 682 & 55 & 737 \\
\hline
\end{tabular}

Source: Royal College of Physicians Consultant Census. ${ }^{6}$

the British Cardiac Society, and none was elected to Council until 1996. When the Presidents of Affiliated Groups joined Council in 1998, four women entered Council, but only one was a cardiologist. Representation is currently static with two female cardiologists and three other women professionals on Council. The Cardiology Committees of the Royal College of Physicians have fared a little better: six of 48 (12.5\%) committee members between 1993 and 2003 were women. Women have always been underrepresented on the various committees of the British Cardiac Society (including abstract selection panels), and the 2002 expansion of committee activity, which increased to $10 \%$ of serving women, was achieved only through multidisciplinary involvement.

\section{WOMEN IN CARDIOLOGY: WHAT ARE THE SOLUTIONS?}

\section{Accept that we have a problem}

Although there is no evidence of discrimination against women in selection for medical school or cardiology SpR rotations, the Working Group believes that many women are being "turned off" the specialty based on the mismatch between career aspirations of female medical graduates and applications to cardiology SpR rotations. This may reflect a number of factors:

- Informed choice that women make having observed the long, family unfriendly hours that cardiology trainees often have to work, coupled with the unavailability of childcare facilities in most hospitals in this country

- Unavailability and active discouragement of flexible training programmes and part time consultant posts

- Paucity of female role models. As one respondent to the consultant questionnaire said: "Support and flexibility of working conditions would improve if there was a critical mass of women cardiologists and female mentors" (see appendix)

- Active discouragement of women within a male dominated specialty.

- Concerns about radiation exposure and fetal safety.

Regardless of the cause, the failure of cardiology to attract women when the gender ratio of medical undergraduates is approximately balanced indicates that a substantial proportion of the talent pool is being lost to other specialties. If this is not corrected it will prove increasingly difficult to maintain high standards of cardiological practice and research in this country. The Working Group considers that acceptance of this problem is a vital first step if corrective strategies are to be adopted.

\section{Establish female mentors locally and nationally}

The Working Group sees provision of a network of specialists for mentoring female trainees as vital for encouraging women to apply for cardiology training programmes and for retaining them within those programmes.

In 1998, postgraduate clinical tutors were advised by their deaneries to set up an optional mentoring system within trusts, in addition to the specialty college tutors and educational supervisors already responsible for junior staff. The Working Group endorses this advice but also considers that a deanery based national network of mentors should be established to help those trainees (mostly women) who need guidance about organisation of flexible training programmes. Female cardiologists or flexible training representatives on higher specialist training committees (STCs) for cardiology are seen as being particularly suitable for this purpose. In addition, the Working Group considers that a female cardiologist on the Specialist Advisory Committee (SAC) should be identified to coordinate promotion of the specialty to would-be women trainees.

The Working Group recognises that female consultants may also benefit from independent offsite mentoring in the event of unwelcome gender-at-work issues. For this purpose the British Cardiac Society and Combined Specialty Committee of the Royal College of Physicians should combine to appoint a senior female consultant with authority to liaise with local medical directors, directors of human resources, and trust management as appropriate.

\section{Encourage flexible training}

One of the few respondents to the consultant questionnaire (see appendix) who replied "no" when asked if she would recommend cardiology to a female senior house officer (SHO) commented that cardiology is "too family unfriendly". This perception is almost certainly commonplace among potential applicants to training programmes and reflects the culture of long hours that deters many women who wish to combine their career choice with raising a family. ${ }^{8}$ Cardiology may become more family friendly with introduction of the New Deal, European Working Time Directive, and Improving Working Lives, ${ }^{7}$ initiatives that are bringing more reasonable working hours for all trainees. These initiatives, however, will not always provide sufficient spare time for the early years of childcare, and flexible training is likely to remain an important means of fulfilling this requirement for many potential applicants, particularly women.

Flexible trainees are inevitably more difficult to accommodate within training programmes and are not always welcomed by trusts (see above). Perhaps for this reason popular specialties such as cardiology, which at present have no shortage of high quality applicants, do not feel driven to appoint flexible trainees, the UK Deaneries database listing only six in 2002. These attitudes towards flexible training are unhelpful and are likely to deter many women from applying.

Job sharing provides an alternative model for supporting flexible trainees. It is more easily assimilated into existing programmes than supernumerary part timers and provides better quality training in jobs more favourably perceived by colleagues. Unfortunately, however, job sharing is not a realistic solution to the problem because it can only be organised when there is a critical mass of local applicants who wish to train flexibly. Thus, current energies must be focused on increasing the availability of supernumerary funding, and programmes must be designed to allow experience across all relevant subspecialties on a fortnightly or monthly (rather than weekly) timetable. The inclusion of formal training and educational events remains mandatory.

The Working Group calls for extension of flexible training opportunities, particularly job sharing schemes where feasible. However, the Working Group emphasises that this will serve the interests of women only if principles of gender equality inform how these jobs are structured and organised. ${ }^{10}$ Higher STCs should appoint a flexible training representative to attend regular meetings with the regional associate dean for flexible training. All trainees should receive information on flexible training and be encouraged 


\section{ACTION POINTS}

- Establish mentors for women in cardiology:

- Trust based

- Deanery based

- Specialty based (British Cardiac Society)

- Encourage flexible training:

- STC based flexible training representatives

- Supernumerary funding sought from deaneries

- Job share opportunities sought

- Establish more part time consultant posts

- Improve access for women to popular subspecialties such as intervention

- Refuse to tolerate sexism or gender based discrimination in the work place

on appointment or in appraisal to declare as necessary their need for it. In this event, the flexible training representative of the regional STC should be called in to facilitate the needs of the trainee. Mentors and role models are crucial here to advise the trainee and help her (or him) achieve the appropriate flexible training objective.

Finally, increments in training time to compensate for flexible programmes often appear harsh, almost punitive. In the new era of competency based training this must be reviewed, with training time tailored to need according to individual competency assessment. This would ensure that competent trainees can emerge from flexible programmes without necessarily having to endure overly prolonged traineeships.

\section{Increase part time consultant posts}

The Working Group sees arguments for part time consultant posts as being broadly similar to those for flexible training. The need is reflected in the consultant questionnaire, which showed that $27 \%$ of respondents were either working part time or considering changing to part time work, the large majority identifying children as the reason for this. More compelling were the responses of SpRs, $83 \%$ of whom were considering working part time on completion of their training (see appendix). Failure to accommodate these doctors may cause considerable workforce problems, which has prompted the setting up of the Flexible Careers Scheme as part of the Improving Working Lives Initiative. ${ }^{7}$ This scheme is available for flexible trainees (see above) and for recently appointed consultants who wish to work part time (up to eight sessions a week). It will fund the first three years of a consultant post at a rate of $50 \%$ in the first year, $25 \%$ in the second, and $10 \%$ in the third. Further tenure must be established after this funding ceases. The potential benefits of the scheme to both cardiologists and trusts is clear, helping to soften the transition to more flexible working in a specialty not accustomed to such practices.

The option of part time working should be considered for every new consultant post and is particularly easy to accommodate when potentially suitable candidates who have already expressed an interest in job sharing are applying. Some job plans designed to fulfil particular departmental needs may lend themselves well to part time working, but the Working Group again emphasises that the interests of women will be served only if principles of gender equality inform how these jobs are structured and organised. To some extent, part time opportunities will increase with the diminishing commitment of cardiologists to general medical take and the adoption of programmed activities, whereby job plans can be more closely aligned to reimbursement within the new consultant contract. Job plans can be further refined to meet individual needs of part time consultants with various options put forward in the Improving Working Lives programme. $^{7}$ These include annualised hour agreements, reduced hours options, self-rostering shifts, career breaks, practical help with childcare and other caring responsibilities, flexible and part time working, and flexible retirement.

The establishment of more part time consultant posts is seen by the Working Group as vital for increasing recruitment of female cardiologists. However, the success of these jobs will depend not only on the provision of imaginative and stimulating job plans but also on the attitudes of those who continue to work full time. Thus, part time working should be recognised as a career friendly option with the potential to fulfil the needs of both men and women to manage a healthy and productive balance between work and life outside. ${ }^{10}$

\section{Open up cardiological subspecialties to women}

There is a perception that women are discouraged from involvement in some of the popular subspecialties, particularly coronary intervention and electrophysiology. Thus, female respondents to the consultant questionnaire (see appendix) quoted "bias against intervention", citing it as "less easy to perform....as a career aim [than non-invasive cardiology]". This is consistent with the findings of an American College of Cardiology survey in 1998, which reported that significantly fewer women were working as interventional cardiologists ( $10 \%$ female $v 27 \%$ male) or as invasive cardiologists ( $18 \% \vee 41 \%$ ), even though more women were working as clinical cardiologists. ${ }^{11}$

Factors that may influence the gender imbalance among interventional cardiologists merit consideration.

\section{Radiation exposure}

The Working Group concluded that any concerns about fetal risk that may deter women from practising interventional cardiology or electrophysiology are largely unfounded. Thus, the health and safety regulations that apply to catheterisation laboratories are protective of all personnel, regardless of gender, provided the appropriate protective measures are taken. Cardiological procedures result in exposures (beneath lead aprons) well below $6 \mathrm{mSv} / \mathrm{year}$, the level that defines a "classified worker" (Ionising Radiation Regulations 1999). Doses for invasive cardiologists in the USA range from 0.7 to $1.6 \mathrm{mSv} /$ year. $^{12}$

Gonadal exposure of $2 \mathrm{mSv}$ (unusually high if lead aprons are worn) in a non-pregnant woman working in the catheterisation laboratory carries a negligible risk of serious birth defects in future offspring, calculated as 4-6 $\times 10^{-6} .^{12}$ On notification of pregnancy, UK employers must ensure that the total gestational dose to the fetus does not exceed $1 \mathrm{mSv}$ (equivalent to $2 \mathrm{mSv}$ to the pregnant abdomen) (Ionising Radiation Regulations 1999). This is a reassuringly cautious limit (in the USA the limit is $5 \mathrm{mSv}$ ) but, in practice, invasive cardiologists receive a total gestational abdominal dose of about $1.2 \mathrm{mSv}$ or less, depending on workload, ${ }^{12}$ equating to a risk of congenital malformation or subsequent malignancy of only one in $4166(0.024 \%) \cdot{ }^{13}$ In short, therefore, there is a large safety margin for pregnant women who wish to continue interventional work in the catheterisation laboratory, provided appropriate protective measures are taken.

\section{Competency issues}

Cardiology is increasingly a procedure driven specialty, comparable in some respects with surgical specialties, many 
of which have never managed to attract significant numbers of women. However, the Working Group did not consider the "manual dexterity" component of cardiological practice a credible reason for deterring women from the specialty. It is noteworthy that, among applicants for surgical posts, women often outperform male colleagues in psychometric tests of spatial reasoning, though tending in many cases to underestimate their capability. ${ }^{14}$ Certainly, there is no evidence that surgical capability is defined by gender and no reason, therefore, why procedural competency should exclude more women than men from cardiology or any of its subspecialties, including intervention and electrophysiology. Indeed, all cardiology trainees must now fulfil the same competency criteria before gaining their Certificate of Completion of Specialist Training. If trainees, male or female, require different degrees of training in particular subspecialties, our programmes should be sufficiently adaptable to meet this requirement and the requirements of those who wish to train flexibly.

Work patterns and lifestyle issues

Managing childcare while pursuing a career in interventional cardiology does, without doubt, provide some interesting challenges. Very few of the women from all walks of cardiology who were questioned by the American College of Cardiology ${ }^{13}$ managed their childcare without help (66\% paid for part or full time care in the home). The on-call commitments of interventional cardiologists are already significant but, if they become more onerous as primary angioplasty rotas are introduced, the negative impact on family life will inevitably increase. However, the Working Group speculated that these pressures on family life may be tempered by the need to develop partial shift work to staff 24 hour rotas while satisfying the requirements of the European Working Time Directive. This would facilitate incorporation of part time consultants into the interventional cardiology service, paradoxically making it a more attractive subspecialty option for women.

In summary, the Working Group found no justification for discouraging women from pursuing careers in any of the cardiological subspecialties, including interventional cardiology and electrophysiology, there being no convincing case on grounds of competency or fetal risk for discrimination of this sort. Although women and men need to consider the impact of antisocial hours on family life, the imperatives of the European Working Time Directive can be expected to minimise this, while changes in the provision of interventional services may facilitate the incorporation of part time workers into on-call rotas.

\section{Refuse to tolerate sexism}

The contribution of sexism and gender based discrimination to the under-representation of women in cardiology is hard to determine but may be significant by analogy with male dominated surgical specialties. ${ }^{15}$ Thus, $46 \%$ of respondents to the consultant questionnaire considered career prospects were worse for female than for male trainees, $43 \%$ reported gender bias at work, and $24 \%$ considered that their gender had interfered with career progression; responses to the SpR questionnaire were similar (see appendix). Nevertheless, there is no evidence of gender bias in recruitment to cardiology training programmes and, as more women become consultants, it is reasonable to assume that the working environment and career prospects for women will improve. Meanwhile, the Working Group emphasises that the sexist attitudes explicit in some of the responses to the consultant questionnaire in the appendix- "I was told (by a senior consultant) as an SHO...not to do cardiology because I was a girl" - are offensive and unacceptable. If a complaint against a member is substantiated, the British Cardiac Society will not hesitate in reviewing the membership of the offender. Moreover, the Society will provide support for any member who has been discriminated against on the grounds of gender or who has been subject to unwelcome sexist behaviour at work.

\section{CONCLUSION}

One of the most telling and consistent responses to the consultant and SpR questionnaires was that nearly all would recommend a career in cardiology to a female SHO considering entering the specialty. Thus, despite the gender related difficulties that many of the respondents reported, it seems clear that a career in cardiology can be as fulfilling for women as for men. Indeed progressively more women are being selected for training programmes and it is inevitable that this trend will continue given the small excess of women now in medical school and junior hospital jobs. The action points recommended by the Working Group will facilitate this process and in doing so will encourage the most talented trainees, regardless of gender, to enter cardiology, invigorating the specialty and helping to maintain the highest standards of clinical practice, teaching, and research.

\section{ACKNOWLEDGEMENTS}

Thanks to Dr Amanda M Varnava for help with the Flexible Careers Scheme and to Ms Rosemary Weston for managerial assistance.

\section{Authors' affiliations}

A D Timmis, C Baker, S Baneriee, A L Calver, A Dornhorst, K M English, J Flint, M E Speechly-Dick, D Turner, British Cardiac Society, London, UK

Correspondence to: Professor Adam D Timmis, London Chest Hospital, Department of Cardiology, Bonner Road, London E2 9JX, UK; timmis@ Ich.demon.co.uk

Accepted 19 July 2004

\section{APPENDIX}

Note: the questionnaires were sent only to female cardiologists (consultants and trainees) with no male control group. For this reason the responses to the questionnaires have been used to illustrate the third part of the report only (Section C), and do not form any part of the factual basis from which our conclusions were drawn.

\section{CONSULTANT QUESTIONNAIRE}

\section{Examples of perceived gender interference or bias} and other comments provided by female consultants responding to the questionnaire

- Difficulty finding part time training.

- Delayed offer of research post...but my major concern was inappropriate discouragement made at SHO level, which may put off young doctors of good potential.

- Not shortlisted for consultant post because consultant would not work with woman.

- Disinvited to apply for a consultant post...advised to go abroad.

- I have had to change to part time work because of children.... As a junior discouraged from pursuing cardiology career.

- Some bias against intervention.

- I was told (by a senior consultant) as an SHO...not to do cardiology because I was a girl.

- The academic atmosphere is not one of equal opportunity.

- General old school tie attitude-have been able to overcome it. 


\begin{tabular}{|c|c|}
\hline \multicolumn{2}{|c|}{$\begin{array}{l}\text { Responses to questionnaire sent to } 65 \text { female consultan } \\
\text { cardiologists, of whom } 37(57 \%) \text { responded }\end{array}$} \\
\hline Appointed $\geqslant 1990$ & $31(84 \%)$ \\
\hline Part time contract ( $<10$ sessions/week) & $5(14 \%)$ \\
\hline Considering changing to part time contract & $4(11 \%)$ \\
\hline \multicolumn{2}{|l|}{ Why part time or considering changing? } \\
\hline Children & $8(89 \%)$ \\
\hline Other & $1(12 \%)$ \\
\hline \multicolumn{2}{|l|}{ Part time training encouraged? } \\
\hline Yes & $1(3 \%)$ \\
\hline No & $34(92 \%)$ \\
\hline Uncertain & $2(5 \%)$ \\
\hline \multicolumn{2}{|l|}{ Has gender interfered with career progression? } \\
\hline Yes & $9(24 \%)$ \\
\hline No & $26(71 \%)$ \\
\hline Uncertain & $2(5 \%)$ \\
\hline \multicolumn{2}{|c|}{ Have you encountered gender based bias at work? } \\
\hline Yes & $16(43 \%)$ \\
\hline No & $18(49 \%)$ \\
\hline Uncertain & $3(8 \%)$ \\
\hline \multicolumn{2}{|c|}{$\begin{array}{l}\text { Are career prospects for female specialist registrars } \\
\text { comparable with those for male specialist registrars? }\end{array}$} \\
\hline Comparable & $18(49 \%)$ \\
\hline Worse & $17(46 \%)$ \\
\hline Better & 0 \\
\hline Uncertain & $2(5 \%)$ \\
\hline \multicolumn{2}{|c|}{$\begin{array}{l}\text { Would you recommend cardiology to a female senior } \\
\text { house officer? }\end{array}$} \\
\hline Yes & $30(81 \%)$ \\
\hline No & $6(16 \%)$ \\
\hline Uncertain & $1(3 \%)$ \\
\hline
\end{tabular}

- Cardiology is "too family unfriendly" ( therefore would not recommend it to female SHO).

- If women are not pursuing a path in cardiology because we are making it too difficult, we should be doing all we can to make it easier PROVIDED we offer the same opportunities to men who wish to train or work part time.

- Most minor instances where gender works against one are balanced by other positive occurrences-it comes out about even.

- I would probably be the last to know (has gender interfered with your career progression?).

- Less easy to perform [percutaneous coronary intervention] as a career aim.

- Gender bias probably no more than in other competitive fields.

\section{SPECIALIST REGISTRAR QUESTIONNAIRE}

Note: this questionnaire was sent only to female cardiologists with no male control group. For this reason the responses to the questionnaire have been used to illustrate the third part of the report only (Section C), and do not form any part of the factual basis from which our conclusions were drawn

\section{Responses to discursive questions provided by female SpRs responding to questionnaire}

Have you had to change career aspirations?

- Not yet!

- I decided several years ago not to train in areas where I might spend a lot of time in the cath lab (radiation risk, etc) and I've always been interested in imaging so I pursued it.

- Because it has been made clear that for a woman a career in hard nosed cardiology is incompatible with family.

- Initially I was particularly interested in intervention. I now realise that it's difficult for women to succeed in this field, as it tends to be dominated by "the boys" playing with
Responses to questionnaire sent to 44 female specialist registrars (SpRs), of whom 24 (55\%) responded

\begin{tabular}{ll} 
Appointed $\geqslant 2000$ & $13(57 \%)$ \\
Flexible training (<10 sessions/week) & $3(13 \%)$ \\
Considering changing to part time contract & $4(20 \%)$ \\
Why part time or considering changing? & \\
Children & $6(86 \%)$ \\
Other & $1(14 \%)$ \\
Part time training encouraged? & $3(13 \%)$ \\
Yes & $20(83 \%)$ \\
No & $1(4 \%)$ \\
Uncertain & \\
Are you considering working part time as a consultant? & $20(83 \%)$ \\
Yes & $4(17 \%)$ \\
No & $13(54 \%)$ \\
Subspecialty aspirations & $4(17 \%)$ \\
Intervention & $12(50 \%)$ \\
Electrophysiology/pacing & $8(33 \%)$ \\
Non-invasive imaging & $5(21 \%)$ \\
Heart failure & \\
Grown up congenital heart disease & $6(25 \%)$ \\
Have you had to change subspecialty aspirations? & $16(67 \%)$ \\
Yes & $2(8 \%)$ \\
No & $10(42 \%)$ \\
Uncertain & $14(58 \%)$ \\
Have you encountered gender based bias at work? & \\
Yes & \\
No & $13(54 \%)$ \\
Are career prospects for female specialist registrars \\
comparable with those for male specialist registrars? \\
Comparable & $10(42 \%)$ \\
Worse & $1(4 \%)$ \\
No response & \\
Would you recommend cardiology to a female senior & \\
house officer? & \\
Yes & $1(4 \%)$ \\
No & \\
No response & \\
\hline & \\
\hline
\end{tabular}

their toys. I would rather be successful in a different field than come second best in intervention.

- Intervention is too difficult to find time and space to train amidst the competition. It is expected of the trainee to spend more than average prescribed hours to achieve this, which is difficult for a woman with a family.

- I was intending to train in intervention but I wanted a family. However, I am pleased I changed tactic.

Have you experienced gender bias in your training?

- Career intentions not taken seriously. Not being given same opportunities for training-invariably in the cath lab.

- I wasn't particularly encouraged to train in intervention despite having a lot more angio experience than some other SpRs at the same stage; however, like most things I could probably have done it if I had wanted to. I couldn't say whether this was due to my gender but I suspected it might be.

- More help from support staff. Sometimes difficulty in being taken seriously among other colleagues in other departments (reviewing patients).

- Apart from the inevitable "Nurse, I thought I had to see the registrar before I went home" from patients, I constantly come up against the idea of the "cardiology boys". For example, I've heard other specialities talk about a cardiology referral as "let's get the cardiology boys in". I was also told by a nurse of an instance where several (male) SpRs and one (male) consultant were discussing how a local (female) staff grade wanted to develop a TOE 
[transoesophageal echocardiography] service at her [district general hospital]. The response from the consultant was "she's got no chance of doing that, not when there are so many of the boys around to do TOE". Conversations similar to that do often occur within my earshot. I always protest, and point out that I am one of their SpRs, and not male. I am usually then told "Oh, you're an honorary bloke for cardiology purposes". No I'm not, and have never wanted to be.

- All (a) boys club atmosphere on occasion, particularly in the cath lab.

- Only in my more junior years. Once I was known, I have been respected and supported. Earlier comments have included "we need someone physically up to the job" and "This isn't a job for a girl".

- I have been told on more than one occasion not to mess up my career by having children. I have therefore delayed decisions regarding my family until I am in a position of greater control (ie, consultant), so that my interventional training is not compromised.

\section{REFERENCES}

1 UCAS. Annual datasets. November 2003. Universities \& Colleges Admissions Service. www.ucas.com/figures/ads.html (accessed 21 November 2004).

2 McManus IC. Factors affecting likelihood of applicants being offered a place in medical schools in the UK in 1996 and 1997: retrospective study. BMJ 1998;317:1111-7.
3 Simpson KH, Budd K. Medical student attrition: a 10 year survey in one medical school. Med Educ 1996;30:172-8.

4 British Medical Association. BMA Health Policy and Economic Research Unit. BMA cohort study of medical graduates 1995, 5th report. London: BMA, 2000.

5 Lambert T, Goldacre M, Parkhouse J. Career preferences and their variation by medical school among newly qualified doctors. Health Trends 1996;28:135-44.

6 Royal Colleges of Physicians of the UK. Census of consultant physicians in the UK, 2002. The Federation of the Royal Colleges of Physicians of the United Kingdom, 2002. www.rcplondon.ac.uk.

7 Department of Health. Improving working lives standard. London: Department of Health, 2001.

8 Lefford F. Women doctors: a quarter-century track record. Lancet 1987;i:1254-6.

9 Mcmanus IC, Sproston KA. Women in hospital medicine in the United Kingdom: glass ceiling, preference, prejudice or cohort effect? J Epidemiol Community Health 2000;54:10-6.

10 Coyle A. Women and flexible working in the NHS. Equal opportunities commission working paper series, no 9. 2003. www.eoc.org.uk/research.

11 Limacher MC, Zaher CA, Walsh MN, et al. The ACC professional life survey: career decisions of women and men in cardiology. A report of the Committee on Women in Cardiology. American College of Cardiology. J Am Coll Cardiol 1998; 32:827-35.

12 Pitney MR, Allan RM, Giles RW, et al. Modifying fluoroscopic views reduces operator radiation exposure during coronary angioplasty. J Am Coll Cardiol 1994;24:1660-3.

13 Limacher MC, Douglas PS, Germano G, et al. ACC expert consensus document. Radiation safety in the practice of cardiology. American College of Cardiology. J Am Coll Cardiol 1998;31:892-913.

14 Gilligan JH, Welsh FK, Watts C, et al. Square pegs in round holes: has psychometric testing a place in choosing a surgical career? A preliminary report of work in progress. Ann R Coll Surg Engl 1999:81:73-9.

15 Richardson HC, Redfern N. Why do women reject surgical careers? Ann R Coll Surg Engl 2000;82(9 suppl):290-3.

\section{IMAGES IN CARDIOLOGY}

\section{Quadricuspid aortic valve}

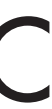
ongenital malformations of the aortic valve are not uncommon. Bicuspid aortic valve is the most common with an incidence of $2 \%$. Quadricuspid valves are rare. Reported incidence varies between 1 in 1000 to 1 in 10000 . Previously this anomaly was detected accidentally during surgery or during necropsy. Now this condition is increasingly being detected with the advent of echocardiography.

A 5 month old male child was referred for evaluation of a cardiac murmur detected on routine physical examination. The child did not have any cardiac symptoms. Physical examination was unremarkable except for a short grade 2 systolic murmur along the left sternal border.

Transthoracic echocardiography revealed a quadricuspid aortic valve with four approximately equal sized cusps

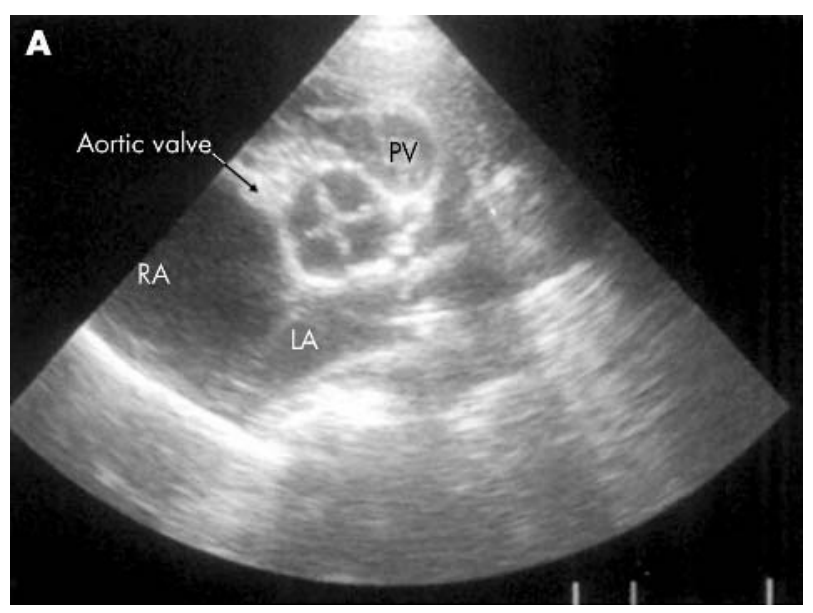

doi: $10.1136 /$ hrt.2004.039289

providing the classical $X$ shaped diastolic short axis commissural pattern (panel A). Full excursion of the leaflets to the margins of the aortic annulus was noted in systole (panel B). The sinotubular junction and ascending aorta were normal. There was no significant stenosis or regurgitation of the aortic valve.

Echocardiography did not reveal any other notable abnormality in the child.

\section{S M Divakaramenon K Venugopal mdsmenon@hotmail.com}

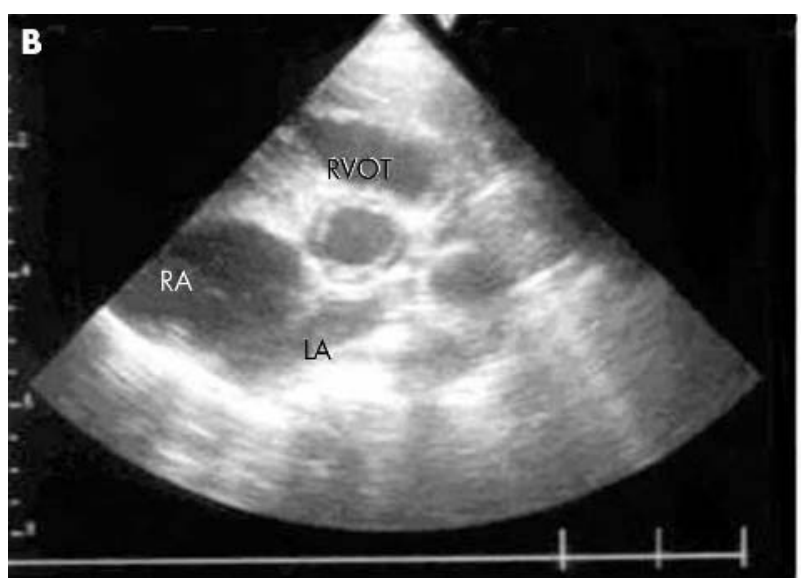

